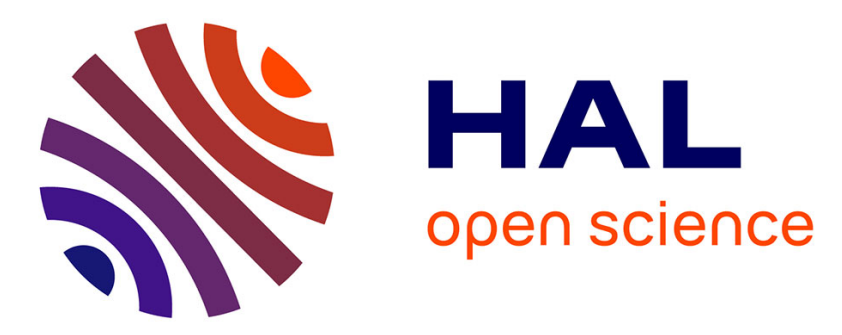

\title{
Effect of loading rate and initial density on the mechanical response of polyurethane elastomer foams
}

A. Lachhab, Eric Robin, Jean-Benoit Le Cam, F. Mortier, Y. Tirel, F. Canévet

\section{- To cite this version:}

A. Lachhab, Eric Robin, Jean-Benoit Le Cam, F. Mortier, Y. Tirel, et al.. Effect of loading rate and initial density on the mechanical response of polyurethane elastomer foams. 9th European Conference on Constitutive Models for Rubbers, (ECCMR IX), Sep 2015, Prague, Czech Republic. hal-02564516

\author{
HAL Id: hal-02564516 \\ https://hal.science/hal-02564516
}

Submitted on 5 May 2020

HAL is a multi-disciplinary open access archive for the deposit and dissemination of scientific research documents, whether they are published or not. The documents may come from teaching and research institutions in France or abroad, or from public or private research centers.
L'archive ouverte pluridisciplinaire HAL, est destinée au dépôt et à la diffusion de documents scientifiques de niveau recherche, publiés ou non, émanant des établissements d'enseignement et de recherche français ou étrangers, des laboratoires publics ou privés.

\section{(c)(1)}

Distributed under a Creative Commons Attribution| 4.0 International License 


\title{
Effect of loading rate and initial density on the mechanical response of polyurethane elastomer foams
}

\author{
A. Lachhab \\ Cooper Standard France, Rennes, France \\ Institut de Physique de Rennes, UMR 6251, Université De Rennes 1, Rennes, France \\ E. Robin \& J.-B. Le Cam \\ Institut de Physique de Rennes, UMR 6251, Université De Rennes 1, Rennes, France \\ F. Mortier, Y. Tirel \& F. Canevet \\ Cooper Standard France, Rennes, France
}

\begin{abstract}
This study deals with the effects of initial density and loading rate on the mechanical response of thermoplastic polyurethane foams under uniaxial cyclic tensile loading. Tests were performed at two different loading rates with five initial density levels. Volume changes were measured during mechanical cycles using the mark tracking method. The mechanical response obtained for each specimen and loading condition has shown that the lower density, the lower the stiffness and the higher the residual strain. Stress softening during the mechanical cycles has been characterized using an energetic approach. Results show that the density has not significant effect on the softening. Moreover, volume change measurements have shown that specimen volume increases significantly with the stretch applied. Volume change strongly depended on the initial density.
\end{abstract}

\section{INTRODUCTION}

Polymer foams are widely used in many applications due to their high energy absorption capacity. For instance, thermoplastic polyurethane foams are used for anti-vibration applications in automotive industry. They feature the mechanical behaviour of rubber and are therefore subjected to phenomena such as softening (Mullins 1948), cavitation (Ball et al. 1981, Diani 2001, Goebel \& Tobolsky 1971, Ramier et al. 2007a, Ramier et al. 2007b), mechanical hysteresis and residual strain.

Even though several studies have investigated inelastic effect in thermoplastic polyurethane (Bartolome et al. 2013, Ugarte et al. 2014), they have not investigated the change in volume induced by stretching while it is a preponderant effect in polymer foams. In the present study, we wanted to completely investigate the mechanical response of thermoplastic polyurethane and thermoplastic polyurethane foams, i.e. stress softening, residual strain, hysteresis and volume change.

\section{MATERIALS AND EXPERIMENTAL SETUP}

\subsection{Elaboration of polyurethane elastomer foams}

The material considered here is a thermoplastic polyurethane. It is denoted TPU in the following. Cells are generated by using a patented process, which consists in mixing TPU with carbon dioxide in its supercritical state during injection. This innovative process ensures the density to be controlled accurately. In order to investigate the effect of the density on mechanical response, several specimens with different densities were elaborated: $1.2,0.724,0.720,0.539$ and 0.519 . They are denoted respectively $\mathrm{d}_{1.2}, \mathrm{~d}_{0.724}, \mathrm{~d}_{0.720}, \mathrm{~d}_{0.539}$ and $\mathrm{d}_{0.519}$ in the rest of the paper. It should be noted that the density of TPU is equal to 1.2. As the specimen volume changes with the mechanical loading (see Section 3.5), the density also varies during the test. This is the reason why the term "initial density" is used in the following. The specimens were obtained by cutting a bar with a water jet cutting device. The gauge section of specimen is $20 \mathrm{~mm}$ 
in length, $9 \mathrm{~mm}$ in width and $5 \mathrm{~mm}$ in thickness. It can be noted that this geometry was chosen to prevent any sliding in the grips. Moreover, the skin formed during the molding of the bar was removed from the specimen. This skin is stiffer than the rest of the specimen and could influence the mechanical response of the specimen.

\subsection{Loading conditions}

Uniaxial tensile loadings were applied using a 5543 Instron testing machine. Figure 1 presents an overview of the experimental device. The specimens were fixed in homemade grips to prevent them from sliding. Mechanical tests were performed by applying five mechanical cycles at four increasing maximum stretch levels: 1.5, 2, 2.5 and 3 . The stretch is defined as the ratio between current and initial lengths. The signal shape chosen was triangular to ensure a constant loading rate during loading and unloading. In order to investigate viscous effects, two loading rates were chosen: $\pm 100 \mathrm{~mm} / \mathrm{min}$ for specimens $\mathrm{d}_{1.2}, \mathrm{~d}_{0.724}$ and $\mathrm{d}_{0.519}$ and $\pm 300 \mathrm{~mm} / \mathrm{min}$ for specimens $\mathrm{d}_{1.2}, \mathrm{~d}_{0.720}$ and $\mathrm{d}_{0.539}$.

\subsection{Stretches and volume change measurements}

The specimen deformation was assumed to be homogeneous in each direction of the test. Stretches were determined by using the track marking method. This method consists in tracking the position of the center of marks at the specimen surface during the test. The reader can refer to Chean et al. (2011) for further information on this method. Two synchronized cameras are used. They observe two perpendicular specimen surfaces. Images are stored at a 5 images/s frame rate. Each pair of marks enables us to determine the stretches $\lambda_{1}, \lambda_{2}$ and $\lambda_{3}$ in direction 1,2 and 3 respectively, which are the principal directions in the present test configuration.

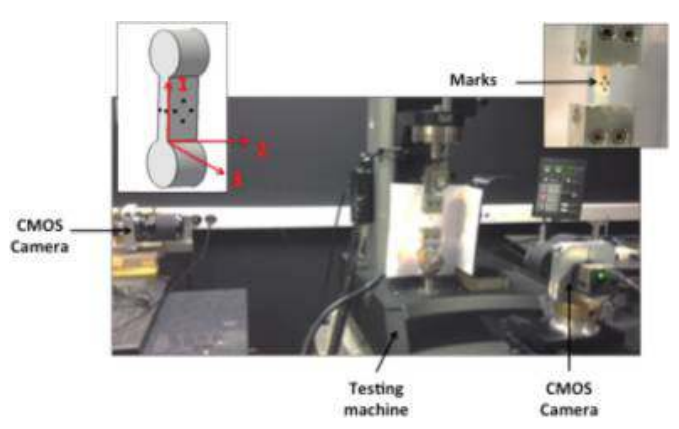

Figure 1. Overview of the experimental setup.

\section{RESULTS AND DISCUSSION}

In this section, results are first presented in terms of stretch-stress response. Softening, residual strain, hysteresis and volume change are discussed with respect to the loading rate and the initial density.

\subsection{Stretch-stress responses}

Results obtained at $\pm 100 \mathrm{~mm} / \mathrm{min}$ and $\pm 300 \mathrm{~mm} /$ min are presented in Figure $2(a, b, c)$ and $(d, e, f)$, respectively. Each diagram gives the nominal stress, defined as the force per initial surface ratio versus the stretch for different initial densities and the loading rates applied. The analyze is carried out by considering specimens $\mathrm{d}_{0.724}$ and $\mathrm{d}_{0.519}$ to be comparable to specimens $\mathrm{d}_{0.720}$ and $\mathrm{d}_{0.539}$, respectively. Firstly, the shape of the mechanical response obtained highlights a strong non-linearity in the stretch-stress relationship. For each loading condition and initial density, inelastic effects were observed: softening, residual strain and hysteresis (see for instance Figure 2(a)). In the next paragraphs, the effects of the initial density and the loading rate on softening, residual strain and hysteresis are more precisely detailed.

\subsection{Softening}

Softening is often considered as a damage phenomenon (Beatty \& Krishnaswamy 2000, Chagnon et al. 2004, De Simone et al. 2001, Diani et al. 2006). Physical interpretation of this effect is provided in a recent study by Diaz et al. (2014) for elastomeric materials. Several studies have evidenced that

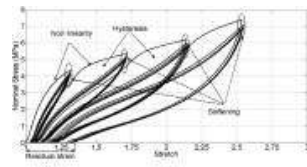

(a)

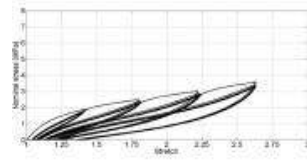

(b)

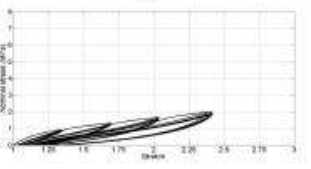

(c)

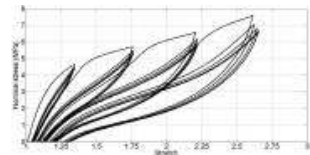

(d)

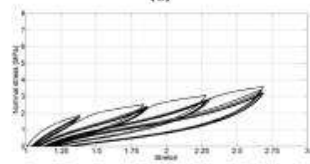

(e)

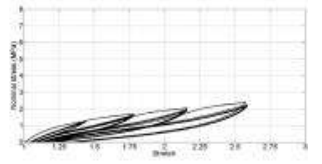

(f)
Figure 2. Mechanical response (stress vs stretch) for a loading rate equal to $100 \mathrm{~mm} / \mathrm{min}$ (a) $\mathrm{d}_{1.2}$ (b) $\mathrm{d}_{0.724}$ (c) $\mathrm{d}_{0.519}$ and $300 \mathrm{~mm} / \mathrm{min}$ (a) $\mathrm{d}_{1.2}$ (b) $\mathrm{d}_{0.720}$ (c) $\mathrm{d}_{0.539}$. 
similar softening occurs in TPU (see for instance Bartelome et al. 2013). Several methods can be used to evaluate the softening, among them that by Stevenson et al. (2001). This method consists in calculating the ratio between the energies brought during first load (W1L) and first unload (W1U) at given maximum stretch applied. In the present study, we have applied another methodology. It consists in calculating the ratio between the energies brought during second (W2L) and first (W1L) loads. This evaluation of the softening was proposed in (Machado et al. 2010). This enables us to remove the effect of hysteresis from the calculation. The measurement of energy is defined by:

$W=\int_{\overline{\bar{F}}} \overline{\bar{\pi}}: d \overline{\bar{F}}$

where $\overline{\bar{\pi}}$ is the nominal stress tensor and $\overline{\bar{F}}$ is the deformation gradient tensor.

Figure 3 presents the evolution of this ratio for different maximum stretches at different initial densities and for loading rate equal to 100 (Fig. 3(a)) and 300 (Fig. 3(b)) $\mathrm{mm} / \mathrm{min}$. By comparing these two figures, the loading rate was found to have no significant effect on the softening in the range of loading rates applied, even though the softening is slightly higher for a loading rate equal to $100 \mathrm{~mm} / \mathrm{min}$. Moreover, the initial density does not significantly affect the softening. For these

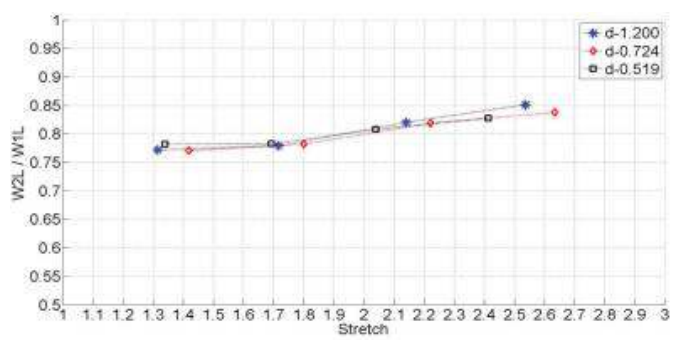

(a)

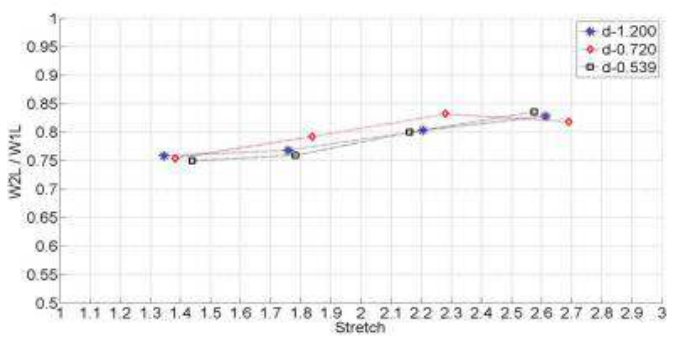

(b)

Figure 3. Influence of the loading rate and the initial density effects on softening (a) $100 \mathrm{~mm} / \mathrm{min}$ (b) $300 \mathrm{~mm} / \mathrm{min}$. three densities, the ratio slightly increases with the stretch, from $76 \%$ at 1.4 to $83 \%$ at 2.6 .

\subsection{Residual strain}

Figure 4 depicts the effect of initial density and maximum stretch applied on residual strain. The five diagrams present the results obtained for each number of cycles in each set of maximum stretch applied. For instance, the diagram entitled "1st cycles" gives the residual strain obtained for the first cycles of each set of maximum stretch applied. The diagrams show that the higher the maximum stretch applied, the higher the residual strain level. The maximum of residual strain was obtained for the first cycles and for the next cycles, the residual strain slightly increased. Moreover, the higher the density, the lower the residual strain at a given stretch. The difference was all the more large that the maximum stretch reached is high. In $\mathrm{d}_{1.2}$ (TPU without cells), the residual strain was stabilized from the third cycle at a given maximum stretch (the effect is illustrated using the dotted line curve). This stabilization was not observed in TPU foams.

Concerning the effect of the loading rate, Figure 5(a) and (b) show that the residual strain for highest and lowest densities was higher for the lowest loading rate.

\subsection{Hysteresis}

Similarly to previous inelastic effects, hysteresis was studied for each density and loading condition. Figure 6 gives the evolution of the hysteresis area between the first load and unload (W1LW1U) versus the maximum stretch applied for the three densities and the two loading rates applied. As shown in Figure 6(a) and (b) for a loading rate equal to $100 \mathrm{~mm} / \mathrm{min}$ and $300 \mathrm{~mm} / \mathrm{min}$ respectively, the hysteresis area highly increases with
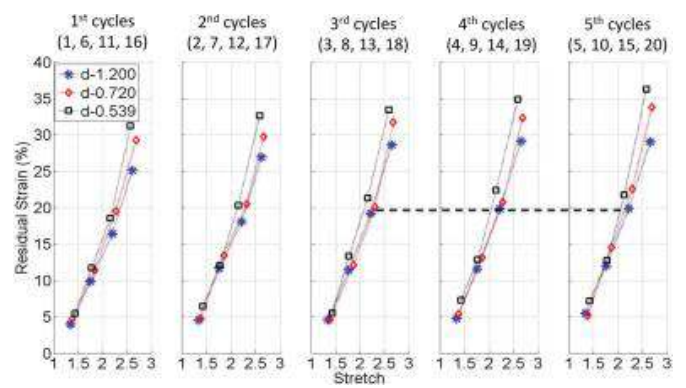

Figure 4. Influence of the initial density on residual strain with respect to the maximum stretch applied and the number of cycles for a given set of cycles. The loading rate is equal to $300 \mathrm{~mm} / \mathrm{min}$. 

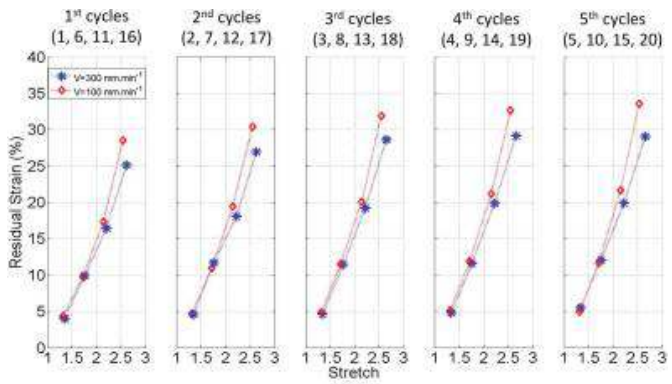

(a)
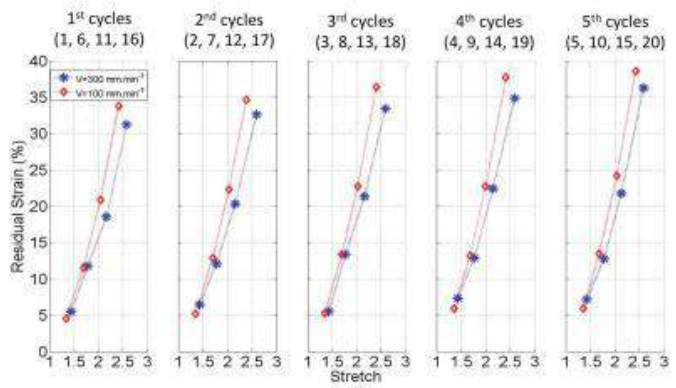

(b)

Figure 5. Influence of loading rate on residual strain (a) $d_{1.2}$ (b) $d_{0.5}$.
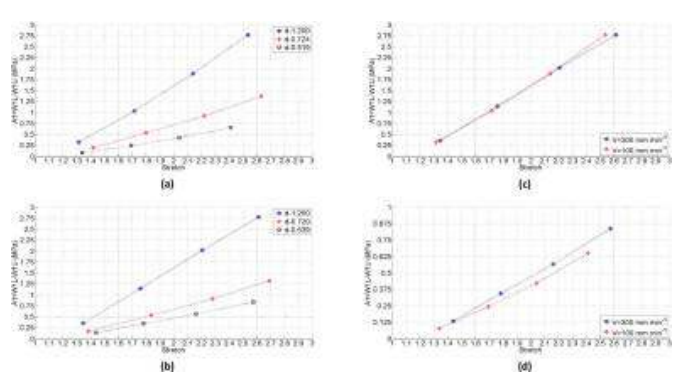

(1)

Figure 6. Influence of the initial density on hysteresis (a) $100 \mathrm{~mm} / \mathrm{min}$ (b) $300 \mathrm{~mm} / \mathrm{min}$. Influence of the loading rate on hysteresis area (c) $\mathrm{d}_{1.2}(\mathrm{~d}) \mathrm{d}_{0.519}$ and $\mathrm{d}_{0.539}$.

the initial density. Figure 6(c) and (d) show that, for the lowest and highest densities, the hysteresis is not significantly affected by the loading rate. Moreover, the ratio between hysteresis at cycles 2, 3,4 and 5 and the hysteresis at cycle 1 for each density and loading rate was quite the same whatever the density considered, but it was highest when the loading rate was lower.

In conclusion to this section, the mechanical response of the TPU studied in the present paper exhibits inelastic effects that is classically observed in filled elastomers: softening, residual strain, hysteresis. This is in a good agreement with the microstructure of TPU, which is a segmented structure that induces inelastic effects in filled as well unfilled TPUs. These inelastic effects were widely studied in the literature (Blundell et al. 2002), (Yeh et al. 2003) and (Unsal et al. 2009) but the comparison between the response of TPU with and without cells has rarely been reported and compared in the literature. In this first part of the paper, we have shown that cells lead to a decrease of hysteresis area, slightly increase the residual strain and do not affect the stress softening. Moreover, no study has reported the change in volume induced by deformation in TPU and TPU foams. This is the aim of the next session.

\subsection{Volume change}

As explained above, polymer foams exhibit significant volume change under deformation. The volume change measurement provides therefore information of importance for improving material formulation and modeling its mechanical behavior. In this section, we present first the effects of loading rate and maximum stretch on the volume change induced by deformation. Then, the effect of initial density are analyzed. A discussion on the origin of anisotropic effects detected is also provided.

The evolution of stretches in the three directions of space during mechanical tests for $\mathrm{d}_{1.2}, \mathrm{~d}_{0.724}$ and $\mathrm{d}_{0.519}$ at $100 \mathrm{~mm} / \mathrm{min}$ has shown that the stretches $\lambda_{2}$ and $\lambda_{3}$ evolved similarly for the highest density. Some differences were detected for $d_{0.724}$. They evolved differently for $\mathrm{d}_{0.519}$. This highlights that anisotropic effects took place and increased with the porosity. The fact that the width and thickness were different and that cell sizes were relatively large compared to the specimen dimensions could make the deformation of porosities different in the corresponding directions. This is the reason why measuring the volume change during deformation requires to measure the stretch in each principal direction.

The volume changes measured during the test were studied with the determinant of the deformation gradient tensor denoted $\mathrm{J}(\mathrm{t})$. It corresponds to the ratio between actual and initial volume: $J(t)=v(t) / v(t=0)$. In case of isotropy or transversal isotropy, the stretches in directions 2 and 3 are equal and the determinant of the deformation gradient tensor writes: $J *(t)=\lambda_{1}(\mathrm{t}) \cdot \lambda_{2}^{2}(\mathrm{t}) ;\left(\lambda_{2}(\mathrm{t})=\lambda_{3}(\mathrm{t})\right)$. In the present study, we wanted to account for possible anisotropy effects. This is the reason why the stretch in the specimen thickness $\lambda_{3}(\mathrm{t})$ was also measured.

Figure 7 illustrates results obtained for $J^{*}(t)$ (isotropy or transversal isotropy) and $\mathrm{J}(\mathrm{t})$ (without 


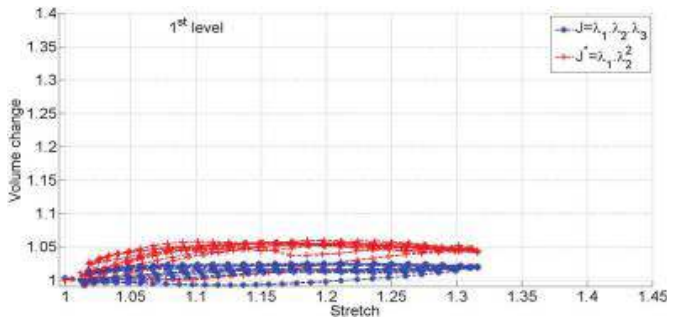

Figure 7. Influence of the transverse isotropy assumption on volume changes calculation for a loading rate equal to $100 \mathrm{~mm} / \mathrm{min}$ (a) 1 st stretch level, $\mathrm{d}_{1.2}$.

any assumption) in case of the first stretch level in $\mathrm{d}_{1,2}$ at $100 \mathrm{~mm} / \mathrm{min}$. This diagram clearly shows that the material does not behave as a transversal isotropic material. Indeed, the volume change measured through $J^{*}(\mathrm{t})$ is higher than $J(t)$. This was observed whatever the stretch level, the initial density and the loading rate. Figure 8 provides $\mathrm{J}(\mathrm{t})$ with respect to the stretch for the five cycles performed at first and fourth maximum stretch levels chosen in specimen $d_{1.2}$ at $100 \mathrm{~mm} / \mathrm{min}$ (Fig. 8(a) and (b)) and $300 \mathrm{~mm} / \mathrm{min}$ (Fig. 8(c) and (d)). In order to investigate the effect of the initial density, results obtained for the lowest initial density, i.e. in specimens $\mathrm{d}_{0.5}$ were considered.

Results that can be summarized as follows:

- the number of cycles at a given stretch level had not significant effect on volume change;

- for the lowest stretch level, the curves exhibited a hysteresis loop in the sense that the loading and unloading paths were different. More particularly, the volume change was higher during the unloading at a given stretch. This was observed whatever the loading rate. This effect was less significant for the lowest initial density or for the last two maximum stretch levels applied;

- for each specimen and loading condition, the higher the stretch level, the higher the volume change, up to $15 \%$ for a stretch equal to 2.55 for specimen $\mathrm{d}_{12}$, and up to a stretch equal to 1.65 for specimen $\mathrm{d}_{0,5}$;

- the higher the initial density the lower the volume change;

- for specimen $d_{1.2}$ the volume change increased at a given stretch if the loading rate was lower;

- a contrario for specimen $\mathrm{d}_{0.5}$, the volume change increased at a given stretch if the loading rate was higher.

These last two observations can be explained by the measurements of stretches in directions $2\left(\lambda_{2}\right)$ and $3\left(\lambda_{3}\right)$.

For specimen $d_{1.2}$, the lower the loading rate, the higher the time for the material to relax and
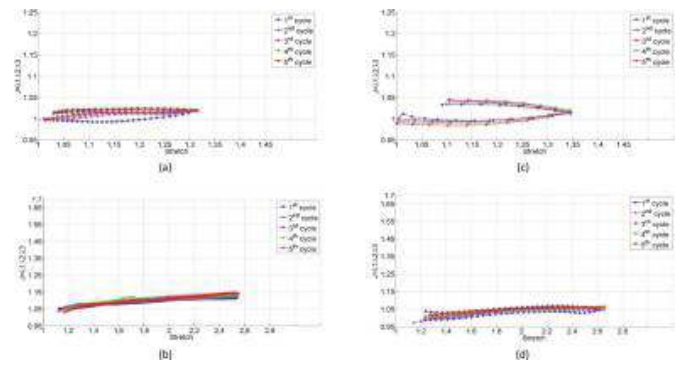

Figure 8. Volume change versus stretch for an initial density equal to 1.2 (a) 1 st stretch level $100 \mathrm{~mm} / \mathrm{min}$ (b) 4th stretch level $100 \mathrm{~mm} / \mathrm{min}$ (c) 1st stretch level $300 \mathrm{~mm} /$ min (d) 4th stretch level $300 \mathrm{~mm} / \mathrm{min}$.

therefore to remove the contraction effect. This effect was expected in such viscous material. For specimen $\mathrm{d}_{0.5}$, stress relaxation leads to a decrease of cell volume, and therefore to a volume decrease, which explains that the higher the loading rate, the higher the volume increase.

\section{CONCLUSION}

The present study deals with the mechanical characterization of TPU foams. A series of cyclic uniaxial tensile tests carried out at different loading rates and different specimen densities. A specific geometry has been designed to avoid any drift in the machine grips. Softening, residual strain, hysteresis and volume change are studied with respect to the loading rate and the initial density. This study shows that significant volume change is observed during deformation of TPU foams. Moreover, it has been shown that stress relaxation acts in opposite way in TPU and in TPU foams. Indeed, loading rate variation has opposite effect on volume changes when cells are present in the material.

\section{ACKNOWLEDGEMENTS}

The authors thank the Cooper Standard France Sompany for supporting this work and for fruitful discussions. The authors thank also the National Center for Scientific Research (MRCT-CNRS and MI-CNRS) and Rennes Metropole for financially supporting this work.

\section{REFERENCES}

Ball, R., M. Doi, S. Edwards, and M. Warner (1981). Elasticity of entangled networks. Polymer 22, 1010-1018. 
Bartolome, L., J. Aurrekoetxea, M.A. Urchegui, and W. Tato (2013, AUG). The influences of deformation state and experimental conditions on inelastic behaviour of an extruded thermoplastic polyurethane elastomer. Materials \& Design 49, 974-980.

Beatty, M.F. and S. Krishnaswamy (2000). A theory of stress-softening in incompressible isotropic materials. Journal of the Mechanics and Physics of Solids 48, 1931-1965.

Blundell, D., G. Eeckhaut, W. Fuller, A. Mahendrasingam, and C. Martin (2002). Real time saxs/stress-strain studies of thermoplastic polyurethanes at large strains. Polymer 43, 5197-5207.

Chagnon, G., E. Verron, L. Gornet, G. Marckmann, and P. Charrier (2004). On the relevance of continuum damage mechanics as applied to the Mullins effect: theory, experiments and numerical implementation. J. Mech. Phys. Solids 52, 1627-1650.

Chean V., Robin E., Abdi R.E., Sangleboeuf J.-C. and Houizot P (2011). Use of the marktracking method for optical fiber characterization. Optics \& Laser Technology; 43, 1172-1178.

De Simone, A., J.J. Marigo, and L. Teresi (2001). A damage mechanics approach to stress softening and its application to rubber. Eur. J. Mech. A/Solids 20, 873-892.

Diani, J. (2001). Irreversible growth of a spherical cavity in rubber-like material: A fracture mechanics description. International Journal of Fracture 112, 151-161.

Diani, J., M. Brieu, and P. Gilormini (2006). Observation and modeling of the anisotropic visco-hyperelastic behavior of a rubberlike material. Int. J. Solids Struct. 43, 3044-3056.

Diaz, R., J. Diani, and P. Gilormini (2014, SEP 15). Physical interpretation of the Mullins softening in a carbon-black filled SBR. Polvmer 55(19), 4942-4947.

Goebel, J. and A. Tobolsky (1971). Volume change accompanying rubber extension. Macromolecules 44, 208-209.
Machado, G., G. Chagnon, and D. Favier (2010). Analysis of the isotropic models of the mullins effect based on filled silicone rubber experimental results. Mechanics of Materials 42, 841-851.

Mullins, L. (1948). Effect of stretching on the properties of rubber. Rubber Chemistry and Technology 21, 281-300.

Qi, H. and M. Boyce (2005, AUG). Stress-strain behavior of thermoplastic polyurethanes. Mechanics of Materials 37(8), 817-839.

Ramier, J., L. Chazeau, C. Gauthier, L. Guy, and M.N. Bouchereau (2007a). Influence of silica and its different surface treatments on the vulcanization process of silica filled SBR. Rubber Chemistry and Technology 80(1), 183-193.

Ramier, J., L. Chazeau, C. Gauthier, L. Stelandre, L. Guy, and E. Peuvrel-Disdier (2007b). In situ sals and volume variation measurements during deformation of treated silica sbr. Journal of Materials Science $42,8130-8138$.

Stevenson, I., L. David, C. Gauthier, L. Arambourg, and J.D.G. Vigier (2001). Influence of sio2 fillers on the irradiation ageing of silicone rubbers. Polymer. 42, 9287-9292.

Ugarte, L., A. Saralegi, R. Fernandez, L. Martin, M.A. Cor-cuera, and A. Eceiza (2014, DEC). Flexible polyurethane foams based on $100 \%$ renewably sourced polyols. Industrial Crops and Products 62, 545-551.

Unsal, E., B. Yalcin, I. Yilgor, E. Yilgor, and M. Cakmak (2009). Real time mechano-optical study on deformation behavior of ptmo/chdi-based polyetherurethanes under uniaxial extension. Polymer 50, 4644- 4655.

Yeh, F., B. Hsiao, B. Sauer, S. Michael, and H. Siesler (2003). In-situ studies of structure development during deformation of a segmented poly(urethane-urea) elastomer. Macromolecules, 1940-1954. 